\title{
Uso do extrato de Myracrodruon Urundeuva Allemão (Aroeira do sertão) no controle do biofilme após gengivectomia com osteotomia suficientemente invasiva: relato de caso
}

\author{
Use of Myracrodruon Urundeuva Allemão extract (Aroeira do sertão) to control biofilm after \\ gingivectomy with sufficiently invasive osteotomy: case report
}
Uso del extracto de Myracrodruon Urundeuva Allemão (Aroeira do sertão) para controlar la biopelícula después de la gingivectomía con osteotomía lo suficientemente invasiva: reporte de caso

Júlia Tavares Palmeira ${ }^{1 *}$, Vitor Nascimento Goes ${ }^{1}$, Ana Beatriz Rodrigues Moura ${ }^{1}$, José Henrique de Araújo Cruz ${ }^{1}$, Itamar da Silva Nunes ${ }^{1}$, Luana Samara Balduino de Sena ${ }^{1}$, Ítalo de Macedo Bernardino", Rodrigo Alves Ribeiro ${ }^{1}$, Rachel de Queiroz Ferreira Rodrigues ${ }^{1}$, João Nilton Lopes de Sousa1.

\section{RESUMO}

Objetivo: Avaliar o uso do extrato aquoso a 10\% produzido da casca de Myracrodruon Urundeuva Allemão (Aroeira do sertão), como bochecho, no controle do biofilme supragengival após gengivectomia com osteotomia suficientemente invasiva. Detalhamento do Caso: Participou do estudo uma paciente de 21 anos, leucoderma, sem alterações sistêmicas e com saúde periodontal em periodonto íntegro que procurou o Projeto de Extensão em Periodontia Clínica e Cirúrgica (PROEPECC) em um município da Paraíba, com queixa de insatisfação estética no contorno gengival. Após a avaliação clínica, periodontal e orientação de higiene bucal, foi realizada a cirurgia plástica na área estética do sorriso (dos dentes 13 ao 23), foi realizado o bochecho de $15 \mathrm{ml}$ do extrato duas vezes ao dia por 14 dias. No pós-operatório de 7, 15 e 21 dias, foram avaliados os índices de placa e de sangramento a sondagem na região operada para observar o acúmulo do biofilme e a inflamação gengival. Considerações Finais: Ao comparar os períodos anterior e posterior a utilização do extrato de aroeira-do-sertão, observou-se uma redução no acúmulo de biofilme e menor inflamação gengival, na área operada, durante o período de utilização do extrato na forma de bochecho.

Palavras-chave: Gengivectomia, Aroeira, Periodontia.

\begin{abstract}
Objective: To evaluate the use of the 10\% aqueous extract produced from the bark of Myracrodruon Urundeuva Allemão (Aroeira do sertão), as a mouthwash, in the control of supragingival biofilm after gingivectomy with sufficiently invasive osteotomy. Case Details: A 21-year-old patient, leucoderma, with no systemic changes and with periodontal health in an intact periodontium who sought the Extension Project in Clinical and Surgical Periodontics (PROEPECC) in a city in Paraíba participated in the study, complained of dissatisfaction esthetics in the gingival contour. After the clinical, periodontal evaluation and oral hygiene guidance, plastic surgery was performed in the aesthetic area of the smile (from teeth 13 to 23), a mouthwash of $15 \mathrm{ml}$ of the extract was performed twice a day for 14 days. In the postoperative period of 7,15 and 21 days, plaque and bleeding rates were evaluated by probing in the operated region to observe the accumulation of biofilm and gingival inflammation. Final Considerations: When comparing the periods before and after the use of aroeira-do-sertão extract, there was a reduction in the accumulation of biofilm and less gingival inflammation, in the operated area, during the period of use of the extract in the form of mouthwash.
\end{abstract}

Keywords: Gingivectomy, Aroeira, Periodontics.

${ }^{1}$ Universidade Federal de Campina Grande Brasileira (UFCG), Patos - PB. *E-mail: julia.palmeira@hotmail.com 


\section{RESUMEN}

Objetivo: Evaluar el uso de extracto acuoso al 10\% producido a partir de la corteza de Myracrodruon Urundeuva Allemão (Aroeira do sertão), como enjuague bucal, en el control de la biopelícula supragingival después de la gingivectomía con osteotomía lo suficientemente invasiva. Detalles del Caso: En el estudio participó un paciente de 21 años, leucoderma, sin alteraciones sistémicas y con salud periodontal en un periodonto intacto que solicitó el Proyecto de Extensión en Periodoncia Clínica y Quirúrgica (PROEPECC) en un municipio de Paraíba, quejándose de insatisfacción estética en el contorno gingival. Luego de la evaluación clínica, periodontal y orientación de higiene bucal, se realizó cirugía plástica en el área estética de la sonrisa (de los dientes 13 al 23), se realizó un enjuague bucal de $15 \mathrm{ml}$ del extracto dos veces al día durante 14 días. En el postoperatorio de 7, 15 y 21 días, se evaluaron las tasas de placa y sangrado mediante sondaje en la región operada para observar la acumulación de biofilm e inflamación gingival. Consideraciones Finales: Al comparar los períodos anteriores y posteriores al uso del extracto de aroeira-do-sertão, hubo una reducción en la acumulación de biopelícula y menos inflamación gingival, en el área operada, durante el período de uso del extracto en forma de enjuague bucal.

Palabras clave: Gingivectomía, Aroeira, Periodoncia.

\section{INTRODUÇÃO}

O sorriso é considerado uma forma universal de comunicação entre os indivíduos independentemente de sua cultura (HUNGUND S, et al., 2012; HUNGUND S, GOHIL D, 2012). Há algum tempo, as pessoas têm se tornado mais exigentes e suas expectativas têm aumentado em relação à estética, fazendo com que a odontologia apresente novas técnicas e materiais para suprir essa necessidade (PEDRON IG, et al., 2010). Ademais, diversos estudos têm apontado que, pacientes que buscam tratamento para alterações gengivais na estética do sorriso apresentam impactos negativos relevantes na qualidade de vida (SALES GB, 2019).

Convencionalmente, as cirurgias para correção do sorriso gengival são realizadas com a elevação de um retalho mucoperiosteal para a exposição óssea e subsequente osteotomia/osteoplastia, de forma a permitir o aumento da coroa clínica (ACC), e consequentemente, a diminuição da exposição gengival (CAMARGO PM, et al., 2017; SOUSA JNL, et al., 2019).

Entretanto, em casos específicos, é possível utilizar uma técnica que não envolve a elevação do retalho (flapless), na qual a osteotomia é realizada com a utilização de micro-cinzéis via sulco gengival (JOLY C, et al., 2011; CRISTOVÁM AVS, et al., 2019).

A cirurgia de aumento de coroa clínica estético pela técnica suficientemente invasiva, na qual a técnica se orienta pela remoção óssea por dentro do sulco gengival sem rebatimento de retalho, apresenta previsibilidade de resultado e reduz possíveis interferências durante o procedimento cirúrgico (RIBEIRO FV, et al., 2014; NUNES IS, et al., 2020).

Esta abordagem reduz o tempo de procedimento, além de apresentar resultados esteticamente favoráveis, desde que o protocolo de execução seja criteriosamente obedecido e respeitada a indicação cirúrgica, que inclui um biótipo ósseo fino ou intermediário, tecido queratinizado abundante e erupção passiva alterada (EPA) como fator etiológico (RIBEIRO FV, et al., 2014).

$\mathrm{Na}$ elaboração de um plano para o sorriso, deve-se atentar a proporção dentária ideal (comprimento $\mathrm{x}$ largura) com fundamento nas características faciais, dentárias e gengivais do paciente, atendendo as suas demandas estéticas, funcionais e psicológicas (NUNES IS, et al., 2020).

Muitos recursos podem auxiliar na elaboração desses planejamentos, um deles é o Digital Smile Designe (DSD), um software capaz de analisar as proporções faciais e dentárias de cada paciente e suas relações com dentes, lábios e gengivas por meio de fotografias digitais e vídeos, além disso, é possível mostrar simulações para ajudar no entendimento dos pacientes, demostrando os benefícios que o procedimento traria e uma previa do resultado final (OKIDA RC, et al. 2017). 
Nas cirurgias periodontais, o digluconato de clorexidina $0,12 \%$ é frequente solicitado como padrão ouro em terapias complementares, no entanto a procura por produtos naturais em detrimento dos químicos tem sido bastante reconhecida ultimamente. Neste contexto, os fitoterápicos vêm se destacando e ocupando cada vez mais espaço nas prateleiras das farmácias.

Inclusive, na periodontia, extratos de plantas medicinais têm sido estudados com o objetivo de substituir a clorexidina no controle químico do biofilme supragengival, pois esta substância apresenta alguns efeitos colaterais locais indesejados, tais como: a formação de cálculo supragengival, perda de paladar e alteração de cor nos dentes (EMÍDIO S, 2010; ALMEIDA AC, et al., 2010).

Dentre os fitoterápicos, a aroeira apresenta um potencial terapêutico no tratamento periodontal que merece ser destacado, justamente por se tratar de um recurso natural em abundância e de baixo custo, possibilitando no futuro uma alternativa de ótimo custo-benefício (JAMES P, et al., 2017; MENEZES TEC, et al 2013).

Além disso, pesquisas demostraram seu efeito como atividade anti-microbiana (PIRES JG, et al., 2018; TRENTIN DS, et al., 2013; PINHO L, et al., 2012) anti-inflamatória (MELLO MJR, et al., 2013; BUENO CRE, et al., 2018; MACHADO AC, et al., 2011), na proteção contra reabsorção alveolar (BOTELHO MA, et al., 2018) e cicatrizante (MELLO MJR, et al., 2013).

Diante disso, o objetivo deste estudo foi relatar um caso clínico de uma paciente submetida a gengivectomia com com osteotomia suficientemente invasiva e utilização do extrato aquoso a $10 \%$ da casca de Myracrodruon Urundeuva Allemão (Aroeira do sertão) no controle do biofilme após procedimento cirúrgico periodontal.

\section{DETALHAMENTO DO CASO}

Este estudo tratou de um relato de um caso clínico de uma paciente, com 21 anos, leucoderma, sem comorbidades sistêmicas, com saúde periodontal em um periodonto íntegro e sem hiperplasia gengival, que procurou o Projeto de Extensão em Periodontia Clínica e Cirúrgica com queixas de insatisfação estética no contorno gengival.

Este caso clínico faz parte de um estudo maior, que foi aprovado pelo Comitê de Ética em Pesquisa com parecer consubstanciado de nํ⒊310.472 e também foi cadastrado no Sistema Nacional de Gestão do Patrimônio Genético e do Conhecimento Tradicional Associado (SisGen) sob nº32F280, em atendimento ao previsto na Lei no13.123/2015 e seus regulamentos.

Foi observado que a paciente em questão, possuía fenótipo periodontal intermediário/ Classe A2, gengiva espessa, posição labial dentro do padrão de normalidade, sem perda de inserção, coroa triangular, mucosa ceratinizada de 3 a $4 \mathrm{~mm}$, papila longa e coroas clínicas dos dentes anteriores e superiores desnivelados ao ser comparado com os dentes homólogos (ROUCK T, et al., 2009). Inclusive a queixa maior da paciente era a evidente desarmonia entre os dentes 11 e 21 (Figura 1 A e B).

Ao se avaliar as linhas estéticas do sorriso, observaram-se as seguintes características: sorriso gengival médio, linha dos zênites gengivais (Ponto mais apical do contorno gengival em cada dente) assimétrica, linha das papilas normal e linha incisal assimétrica no dente 21.

Segundo Alves NV, et al. (2016), alterações nas linhas de referência do sorriso podem torná-lo menos agradável visualmente, sendo necessário a execução de cirurgias periodontais de correção, como o aumento de coroa clínica, gengivoplastia, gengivectomia e recuperação de espaço biológico. A harmonização do sorriso não só melhora o aspecto visual do paciente como também afeta de forma positiva a sua autoestima, e acaba sendo quase como uma exigência fundamental na vida social moderna.

No quadro abaixo, pode-se observar algumas alterações estéticas presente no sorriso da paciente, como também como seria na estética ideal (Quadro 1). Além disso, na análise do sorriso, ficou evidente que a paciente apresentava os zênites gengivais dos incisivos centrais na mesma altura dos incisivos laterais (Figura 1C). 
Figura 1 - Fotografia do aspecto do sorriso antes do tratamento e diagrama de referências estéticas do sorriso da paciente com a demarcação dos zênites gengivais pré-operatórios.

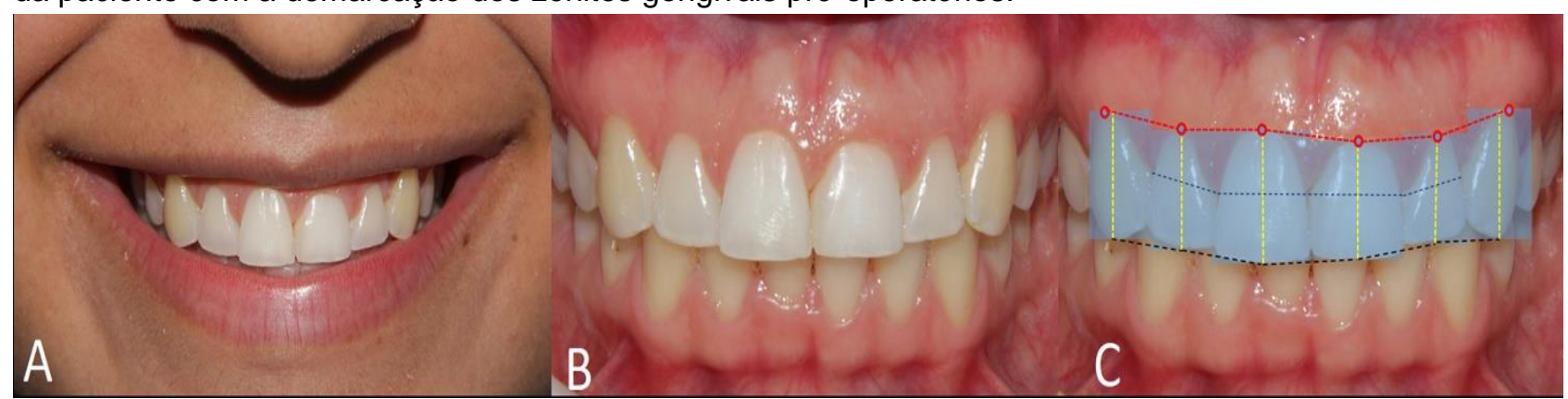

Fonte: Palmeira JT, et al., 2020.

Quadro 1 - Alterações estéticas presente no sorriso da paciente.

\begin{tabular}{|c|c|c|}
\hline Parâmetro & Estética ideal & Condição inicial da paciente \\
\hline Linha cervical & Convexa & Assimétrica \\
\hline Triangulo gengival & Presente & Ausente \\
\hline Zênite dos Incisivos Centrais (IC) & Distalizado & Centralizado \\
\hline Zênite dos Incisivos Laterais (IL) & Centralizado e apical (IC) & Centralizado e na mesmo plano do IC \\
\hline
\end{tabular}

Fonte: Palmeira JT, et al., 2020.

Para Alves NV, et al. (2016), as alterações na coloração dos dentes é outro grande fator que interfere na estética dental, sendo essas alterações de origem intrínseca ou extrínseca. Em casos de escurecimento dental, o tratamento mais recomendado é o clareamento dental, um procedimento que consiste basicamente na aplicação de um gel clareador à base de peróxido de carbamida ou de hidrogênio sobre os dentes que pretende clarear.

No caso em questão, a paciente já apresentava uma coloração satisfatória dos seus elementos dentais e, por não ocorrer alterações de cor após os bochechos com extrato de aroeira, não houve necessidade de clareamento. A cor dos dentes da paciente foi avaliada antes e após 21 dias do procedimento cirúrgico, com auxílio de uma escala Vita Classic ® (Vita, Zahnfabrik, Sackingen, Alemanha), para observar se o bochecho com extrato de aroeira era capaz de produzir alguma coloração nas superfícies dentárias após 14 dias de uso.

$\mathrm{Na}$ avaliação inicial, os dentes anteriores e superiores apresentavam a cor B1 e após 21 dias, permaneceu a mesma cor. A importância da avaliação da escala nesse estudo experimental se baseou na avaliação do extrato possuir ou não a capacidade de pigmentar os dentes. A técnica escolhida para devolver a estética do sorriso da paciente foi a gengivectomia com osteotomia suficientemente invasiva, baseada no artigo de (CRISTOVÁM AVS, et al., 2019) (Figura 4).

O protocolo cirúrgico foi dividido nas seguintes etapas: 1 - avaliação do índice de sangramento gengival; 2 - avaliação do índice de placa; 3 - polimento das coroas coradas com pasta profilática e taça de borracha; 4 - antissepsia extra e intrabucal com digluconato de clorexidina a $2 \%$ e $0,12 \%$, respectivamente; 5 - anestesia terminal infiltrativa utilizando o anestésico mepivacaína com vasoconstrictor; 6 - Marcação dos pontos através da sondagem com o auxílio da sonda periodontal Carolina do Norte na região em que será feita a incisão, são marcados três pontos em cada dente; 7 - União dos pontos demarcados anteriormente através de uma linha tênue feita com bisturi 15c; 8 - Incisão com o bisturi sem bisel; 9 - Incisão intra-sulcular para desprendimento das fibras gengivais; 10 - Remoção do tecido mole e de granulação com curetas de Gracey (5/6); 11 Osteotomia suficientemente invasiva com cinzel de ocheseibein; 12 - Irrigação abundante com soro fisiológico; 13 - Hemostasia; 14 - Orientações pós-operatórias (Figura 2). 
Figura 2 - Pós-operatório imediato da gengivectomia com osteotomia suficientemente invasiva.

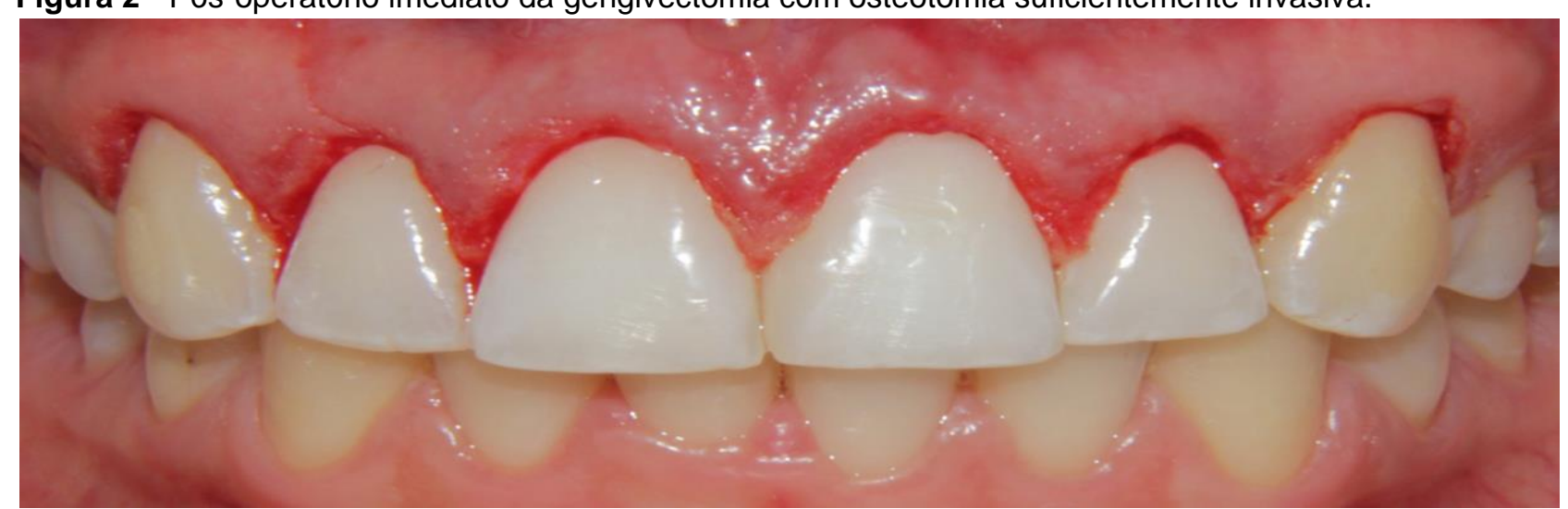

Fonte: Palmeira JT, et al., 2020.

No geral, a aroeira é uma planta medicinal muito utilizada na região nordeste com finalidade terapêutica para infecções e inflamações em geral, dor de cabeça, dor de dente, antisséptico. Normalmente, os residentes dessa região conseguem os extratos da planta através do preparo das folhas, raízes, entrecasca, casca do tronco e galhos (MACHADO AC, OLIVEIRA RC, 2014). A matéria prima (casca do tronco) da Myracrodruon urundeuva Allemão (Aroeira do Sertão), para confeccionar o extrato, foi obtida em um município do sertão do estado da Paraíba (Nordeste do Brasil), área de Caatinga Antropizada, distante $318 \mathrm{Km}$ da capital João Pessoa.

Para o preparo do extrato aquoso foi adaptada a metodologia descrita por Ferris $\mathrm{H}$ e Zeng L (1999). Para isto, em um frasco de vidro tipo Becker com $1000 \mathrm{~mL}$ de capacidade, foram adicionados na balança digital (Marte $\AA$ ) separadamente $50 \mathrm{~g}$ da casca medicinais secas, moídas no próprio moinho da universidade e 500 $\mathrm{mL}$ de água destilada, permanecendo em repouso por 24 horas no Becker envolto de papel alumínio, em temperatura ambiente. Após este período, o extrato aquoso da espécie vegetal foi filtrado separadamente em papel filtro, utilizando-os em seguida. A concentração desejada no estudo foi a $10 \%(100 \mathrm{mg} / \mathrm{ml})$. A paciente foi orientada a bochechar $15 \mathrm{ml}$ do extrato da aroeira, por 1 minuto, duas vezes ao dia, durante 14 dias.

Para avaliar o controle do biofilme (índice de placa - IP) e a inflamação gengival (índice de sangramento à sondagem - ISS e profundidade de sondagem -PS), nos dentes envolvidos no procedimento cirúrgico, utilizaram-se uma avaliação dicotômica ( $\operatorname{sim} / n a ̃ o)$, na qual se calculava a proporção dos sítios com sangramento gengival Chapple ILC, et al. (2018) quando a sonda periodontal PC-15 (Carolina do Norte) era inserida com força controlada no sulco gengival em quatro sítios, sendo três vestibulares (mesial, vestibular e distal) e a face palatina.

De forma semelhante foi calculado a proporção de biofilme aderido à superfície dentária. A profundidade de sondagem foi avaliada medindo a distância entre a margem gengival e na extremidade apical do sulco gengival coma mesma sonda relatada acima. Todos os exames foram realizados por um examinador previamente calibrado.

A necessidade de verificar o controle do biofilme no presente estudo, se baseia na avaliação do potencial antimicrobiano do extrato. Nesse sentido, sendo o biofilme dentário uma massa concentrada de polissacarídeos não calcificados e glicoproteínas, ele acaba sendo um local muito propícios para a fixação e proliferação de microrganismos oportunistas causadores de problemas como a cárie e doenças periodontais, o controle do biofilme pode ser potencializado com o uso adjuvante de antissépticos bucais contendo ingredientes ativos como clorexidina e óleos essenciais (FILOGÔNIO CFB, et al., 2011).

Sobre o índice de sangramento gengival, foi encontrada uma diminuição significativa entre o período préoperatório e o pós-operatório de 15 dias, demonstrando um alto perfil reparador tecidual do extrato durante os 15 dias de utilização. Em relação ao índice de placa, houve uma drástica redução entre o pré e o pósoperatório de 15 dias, desempenhando atividade antimicrobiana. 
Quanto a profundidade de sondagem, houve uma diminuição entre o pré-operatório e o pós-operatório com 15 dias, no entanto, com última reavaliação com 21 dias, aumentou e se estabilizou dentro dos parâmetros clínicos (Tabela 1).

Tabela 1 - Média dos índices de sangramento gengival, índice de placa e profundidade de sondagem.

\begin{tabular}{ccccc}
\hline Índices & Pré-operatório & $\begin{array}{c}\text { Pós-operatório } \\
\text { com 7 dias }\end{array}$ & $\begin{array}{c}\text { Pós-operatório } \\
\text { com 15 dias }\end{array}$ & $\begin{array}{c}\text { Pós-operatório } \\
\text { com 21 dias }\end{array}$ \\
\hline $\begin{array}{c}\text { Índice de } \\
\text { Sangramento Gengival }\end{array}$ & 16,6 & 8,3 & 4,1 & 12,5 \\
Índice de Placa & 33,3 & 4,1 & 8,3 & 8,3 \\
$\begin{array}{c}\text { Profundidade de } \\
\text { Sondagem }\end{array}$ & 1,5 & 2,4 & 1,3 & 1,5 \\
\hline
\end{tabular}

Fonte: Palmeira JT, et al., 2020.

Clinicamente, durante o período de avaliação do estudo, a paciente não relatou nenhum desconforto pósoperatório, como também não houve a necessidade de ingestão de nenhum medicamento com ação analgésica e/ou anti-inflamatória. Observou-se após 7 dias de pós-operatório, um excelente padrão de reparo com ausência de edema, supuração e eritema (Figura 3).

Figura 3 - Aspecto clínico do reparo do tecido gengival no pós-operatório de $7(A), 15$ (B) e 21 dias (C).
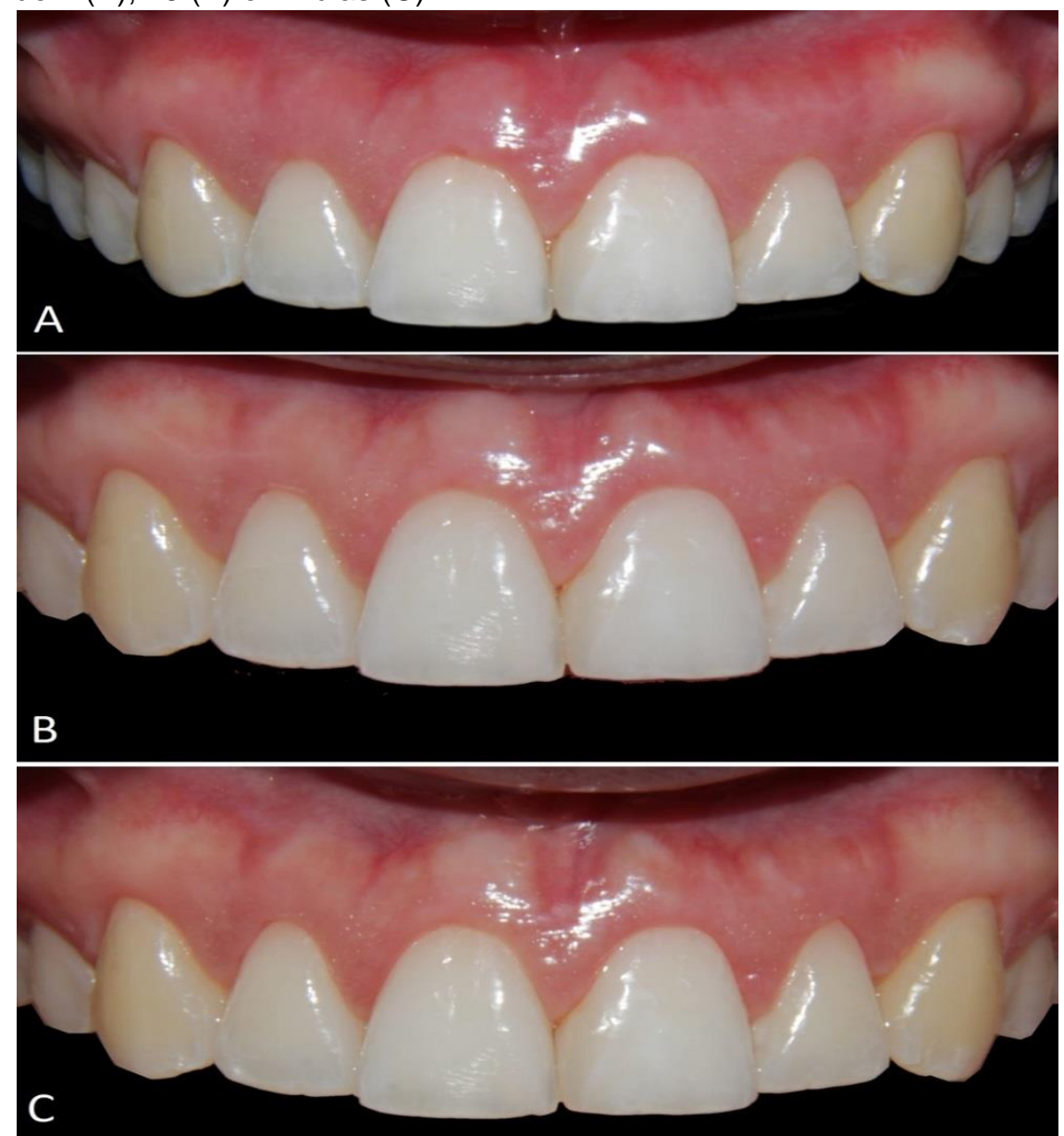

Fonte: Palmeira JT, et al., 2020. 
$\mathrm{Na}$ avaliação de 21 dias, a coloração dos dentes foi novamente avaliada e não houve alteração de cor nos dentes em decorrência da utilização do extrato de aroeira como bochecho pós-operatório por um período de 14 dias (Figura 4).

Figura 4 - Avaliação da cor dos dentes da paciente após 14 dias de bochecho com extrato aquoso de aroeira.

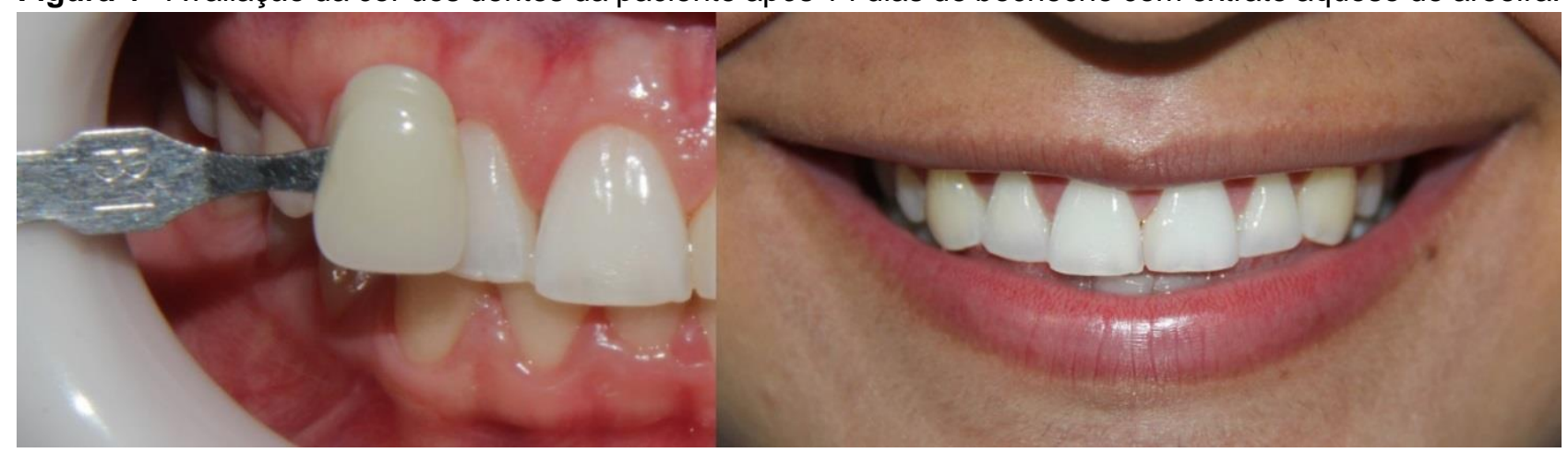

Fonte: Palmeira JT, et al., 2020.

\section{DISCUSSÃO}

Os tratamentos odontológicos com finalidade estética estão se tornando cada vez mais populares, com base nesses aspectos, é notável o desenvolvimento de novos recursos capazes de facilitar a realização dos procedimentos e melhorar a satisfação dos pacientes.

O desenvolvimento e a popularização, especialmente nos últimos anos, de novas técnicas operatórias e materiais odontológicos abriram importante viés para a estetização da saúde em Odontologia, isto é, para a valorização de padrões estéticos como definidores de condições de saúde bucal (REZENDE MCRA e FAJARDO RS, 2016).

Nessa perspectiva, diante da importância dada à estética no convívio social, muitos pacientes recorrem aos tratamentos odontológicos, buscando satisfação pessoal e melhorias na auto-estima (FERNANDES DC, 2016). Nesse contexto, a Periodontia é uma das áreas da Odontologia que desempenha papel essencial na estética facial, tendo em vista que atua na busca de um sorriso harmônico (PIRES CV, et al., 2010). No caso clínico apresentado, a paciente estava insatisfeita com o contorno gengival de alguns elementos dentários e através de um tratamento cirúrgico periodontal conseguiu o sorriso que almejava.

Os procedimentos cirúrgicos periodontais têm recebido destaque por sua diversidade de técnicas cirúrgicas que permitem não apenas uma boa função dos tecidos periodontais, mas também 0 reestabelecimento da estética (SILVA CO, et al., 2015). Nesse contexto, a gengivoplastia consiste em uma remodelação cirúrgica do tecido gengival e papilas para correção de deformidades, com objetivo estético.

Dentre esses procedimentos, a gengivectomia representa uma técnica de aumento de coroa clínica (ACC), que é, muitas vezes, executada com finalidade estética (MALKINSON S, et al., 2013; SMITH MM, 2013; KALSI $\mathrm{HJ}$, et al. 2015). A combinação de diversas técnicas, procedimentos e compostos fitoterápicos também é bastante comum, tanto para auxiliar na execução de um tratamento mais conservador, quanto para melhorar os processos de recuperação e reabilitação.

No contexto das cirurgias periodontais, podemos citar o uso de substâncias que auxiliam no controle dos microrganismos, na diminuição da inflamação tecidual, no controle da dor e também no processo de reparação dos tecidos afetados (VARONI EM, et al., 2012; BOHNEBERGER G, et al., 2019).

Segundo Alvarenga DB, et al. (2018), a percepção de sorriso esteticamente satisfatório, quando a linha do lábio repousa próximo a margem cervical dos dentes anterossuperiores, expondo uma estreita faixa de tecido gengival, representa uma importante preocupação estética tanto para os profissionais como para os pacientes. 
No presente relato de caso, foi realizado uma gengivectomia sem bisel com osteotomia minimamente invasiva, uma vez que o procedimento objetivava melhorar o aspecto harmônico das coroas dos elementos dentários. A profundidade de sondagem apresentou valor equivalente após 21 dias do pré-operatório, indicando que a técnica foi conservadora e o procedimento foi bem-sucedido.

De acordo com Sousa JNL, et al. (2019) a multidisciplinaridade entre as diversas áreas da odontologia é de suma importância para o planejamento e execução do tratamento periodontal, apresentando resultados satisfatórios, visto que propõe a interação entre diversos campos, possibilitando o uso de meios que proporcionem uma estética dental adequada, preservação da saúde dos tecidos periodontais e utilização de métodos com melhores custos-benefícios.

A Fitoterapia tem sido descrita como uma alternativa terapêutica bastante corriqueira na odontologia. Por essa razão, segundo revisão realizada por Maia GRF e Lima CP (2019), a Aroeira do sertão (Myracrodruon urundeuva Allemão) apresenta efeitos antimicrobianos, cicatrizantes, ação contra a Candida e pode ser usado em antissépticos no tratamento de gengivite.

No presente estudo foi utilizado a Aroeira do sertão como bochecho pós-operatório, obtendo-se resultados bastante promissores, ressaltada uma grande vantagem de não haver pigmentação dentária no período de 14 dias de uso do extrato na paciente, justificando a necessidade de mais estudos de interesse odontológico.

No caso apresentado houve uma diminuição no índice de placa após 21 dias de uso do extrato, essa redução pode ter ocorrido em associação as propriedades antibacterianas do Myracrodruon urundeuva. Pires JG, et al. (2019), identificaram uma redução no número de microrganismos do biofilme dental após o tratamento com os extratos de Myracrodruon urundeuva, principalmente redução do $S$. mutans que é um dos principais causadores da cárie e está presente em muitas outras infecções da cavidade oral.

Diversos substratos de origem vegetal são pesquisados e utilizados como recursos adjuvantes no tratamento de pacientes odontológicos, suas propriedades terapêuticas são motivo de interesse de muitos pesquisadores.

Em sua revisão, Goes VN, et al. (2020), realizou um levantamento sobre as propriedades fitoterápicas do Rosmarinus officinalis (Alecrim), identificando uma eficácia no controle do fungo da Candidíase e de diversas bactérias presentes na cavidade oral.

Já na revisão sistemática de Dias JN, et al. (2015), é discutido o potencial de redução do índice de sangramento gengival que fitoterápicos a base de aroeira apresentam, também é identificado que essa planta é muito utilizada pela população da região nordeste do Brasil no tratamento de infeções, dor de cabeça, dor de dente e inflamações em geral.

De acordo com Machado AC e Oliveira RC (2014) a Aroeira tem demonstrado excelentes resultados em análises envolvendo o controle de microrganismos associados a patologias bucais, de forma que a diminuição desses microrganismos se dá pela inibição enzimática e pela precipitação de proteínas que inibem o desenvolvimento microbiano. Os extratos hidroalcoólicos da casca da Aroeira do sertão atuam como antiinflamatórios, analgésicos, antiúlceras, anti-histamínicos e antibradicinínicos (FURTADO GB, 2012).

No presente estudo, posteriormente ao casamento da utilização do extrato, foi realizada uma nova sondagem com 21 dias e foi averiguado um aumento do sangramento gengival, reforçando ainda mais o perfil anti-inflamatório e antimicrobiano do extrato durante o período de utilização (15 dias). Além disso, o extrato apresentou ação satisfatória como potencial cicatrizante dos tecidos periodontais, demonstrando grande relevância para estudos posteriores.

Dentre os efeitos dos fitoterápicos na odontologia, observou-se que o extrato aquoso de Myracrodruon urundeuva Allemão (Aroeira do sertão) a 10\% reduziu os níveis de sangramento gengival e índice de placa durante o período de 14 dias de uso além de não pigmentar a superfície dentária, gerando resultados bastante promissores. Esse estudo ressalta a importância da fitoterapia por meio do grande potencial da aroeira do sertão nos dias atuais e o quanto se torna necessário maiores investimentos em pesquisas nessa área. 


\section{REFERÊNCIAS}

1. ALMEIDA AC, et al. Toxicidade aguda dos extratos hidroalcoólicos das folhas de alecrim-pimenta, aroeira e barbatimão e do farelo da casca de pequi administrados por via intraperitoneal. Cienc Rural. 2010; 40(1): 200-203.

2. ALVARENGA DB, et al. Inter-relação periodontia/dentistica na correção de sorriso gengival: Relato de caso clínico. 2018; 28(2):7-13.

3. ALVES NV, et al. Reabilitação estética e functional do sorriso: revisão de literature. Revista Interfaces. 2016; 3(9):25-30.

4. BOHNEBERGER G, et al. Braz. J. Hea. Rev. 2019; 2 (4): 3504-3517.

5. BOTELHO MA, et al. Efeitos de um gel herbal contendo carvacrol e chalconas na reabsorção óssea alveolar em ratos em periodontite experimental. Phytotherapy Research. 2018; 22(4):442-449.

6. BUENO CRE, et al. Reação tecidual a extratos de Aroeira (Myracrodruon Urundeuva) associados a microorganismos: Estudo in vivo. Braz. Oral Res. 2018; 32(42).

7. CAMARGO PM, et al. Clinical crown lengthening in the esthetic zone. CDA. 2017; 35(7):487498.

8. CHAPPLE ILC, et al. Periodontal health and gingival diseases and conditions on an intact and a reduced periodontium: Consensus report of workgroup 1 of the 2017 World Workshop on the Classification of Periodontal and Peri-Implant Diseases and Conditions. J Clin Periodontol. 2018; 45(20):68-S77.

9. CRISTÓVAM AVS, et al. Correção de contorno gengival pelas técnicas de gengivectomia convencional e minimamente invasiva. Archives Health Investigation. 2019; 8(10): 606-612.

10. DIAS JN, et al. O uso de fitoterápicos à base de aroeira como coadjuvante no tratamento da gengivite: Revisão Sistemática. Rev. bras. plantas med. 2015;17(4): 1187-1191.

11. EMÍDIO S. Oral manifestations of leukemia and antineoplastic treatment - a literature review (part II). Brazilian J. of Health. 2010; 1(1):136-149.

12. FERNANDES DC. Odontologia estética e qualidade de vida: revisão integrativa. Ciências Biológicas e da Saúde. $2016 ; 3$ (3): $91-100$.

13. FERRIS H, ZHENG L. Plant sources of chinese herbal remedies: Effects on Pratylenchus vulnus and Meloidogyne javanica. Journal of Nematology. 1999; 31 (3):241-263.

14. FILOGÔNIO CFB, et al. Effect of vegetable oil (Brazil not oil) and mineral oil (liquid petrolatum) on dental biofilm control. Braz Oral Res. 2011; 25(6): 556-561.

15. FURTADO GB. Avaliação do efeito terapêutico da aroeira do sertão (Myracrodruon urundeuva Allemão) na gastropatia reativa induzida por anti-inflamatórios não esteroides. 2012 [Dissertação de Mestrado em Farmácia]. Fortaleza: Universidade Federal do Ceará; 2012.

16. GOES VN, et al. Applicability of Rosemary (Rosmarinus officinalis) as a potential herbal medicine in Dentistry: a literature review. Research, Society and Development, 2020; 9(7): 1-13, e645974767.

17. HUNGUND $S$, et al. Assessment of smile architecture and pink aesthetics: A successful methodology in cosmetic dentistry. European Journal of General Dentistry. 2012; 1 (2): 85-89.

18. JAMES P, et al. Chlorhexidine mouthrinse as an adjunctive treatment for gingival health. Cochrane Database Syst Ver. 2017; 31(3): 37-38.

19. JOLY C, et al. Flapless aesthetic crown lengthening: a new therapeutic approach. Rev Mexicana de Periodontia. 2011; 2(3): 103-108.

20. KALSI HJ, et al. Uma atualização sobre o alongamento da coroa. Parte 2: Aumento da altura clínica da coroa para facilitar restaurações previsíveis. Atualização Dentária, 2015; 42 (3): 230-236.

21. MACHADO AC, et al. Evaluation of tissue reaction to Aroeira (Myracrodruon urundeuva) extracts: a histologic and edemogenic study. J. Appl. Oral Sci. 2011; 20(4):414-418.

22. MACHADO AC, OLIVEIRA RC. Medicamentos Fitoterápicos na odontologia: evidências e perspectivas sobre o uso da aroeira-do-sertão (Myracrodruon urundeuva Allemão). Rev. Bras. PI. Med. 2014; 16 (2): 283-289.

23. MAIA GKF, LIMA CP. O uso de plantas medicinais na odontologia: revisão de literatura. In: Anais do EVINCI, 2019, Curitiba. UniBrasil; out. 2019, p. 356-356.

24. MALKINSON S, et al. O efeito do alongamento da coroa estética nas percepções da atratividade, simpatia, confiabilidade, inteligência e autoconfiança de um paciente. Journal of Periodontology, 2013; 84 (8): 1126-1133.

25. MELLO MJR, et al. Atividade anti-inflamatória, cicatrizante e antimicrobiana do extrato aquoso de aroeira-do-sertão a $20 \%$ (myracrodruon urundeuva fr. All.), aplicado em fraturas expostas induzidas em mandíbula de coelho. Rev. Cir. Traumatol. Buco-Maxilo-fac. 2013; 13(1): 97-104.

26. MENEZES TEC, et al. Protective efficacy of Psidium cattleianum and Myracrodruon urundeuva aqueous extracts against caries development in rats. Pharmaceutical Biology. 2010; 48(3): 300-305.

27. NUNES IS, et al. Utilização do Digital Smile Design para a correção da estética vermelha do sorriso com técnica cirúrgica suficientemente invasiva. Revista Eletrônica Acervo Saúde. 2020; 1(47): e3127.

28. OKIDA RC, et al. A utilização do DSD (Digital Smile Design) para a otimização da estética dental. Rev. Odontol. Araçatuba. 2017; 38(3): 9-14.

29. PEDRON IG, et al. Sorriso gingival: Cirurgia ressectiva coadjuvante à estética dental. Odonto. 2010; 18 (35): 87-95.

30. PINHO L, et al. Atividade antimicrobiana de extratos hidroalcoolicos das folhas de alecrim- pimenta, aroeira, barbatimão, erva baleeira e do farelo da casca de pequi. Ciência Rural. 2012; 42(2):326-331.

31. PIRES CV, et al. Procedimentos plásticos periodontais em paciente com sorriso gengival - relato de caso. Revista Periodontia. 2010; 20 (1): 48-53.

32. PIRES JG, et al. Effect of hydroalcoholic extract of Myracrodruon urundeuva All. And Qualea grandi flora Mart. Leaveson the viability and activity of microcosmo biofilm and on enamel demineralization. J Appl Oral Sci. 2019; 27: e20180514.

33. REZENDE MCRA, FAJARDO RS. Abordagem estética na Odontologia. Arch Health Invest. 2016; 5(1): 50-55.

34. RIBEIRO FV, et al. Open-flap versus flapless esthetic crown lengthning: 12-month clinical outcomes of a randomized controlled clinical trial. J Periodontol. 2014; 85(4):536-544.

35. ROUCK T, et al. The gingival biotype revisited: transparency of the periodontal probe through the gingival margin as a method to discriminate thin from thick gingiva. Journal of clinical periodontology, 2009; 36(5): 428-433.

36. SALES GB, et al. Impacto na qualidade de vida de cirurgia de aumento de coroa clínica em área estética associada ou não à laserterapia de baixa intensidade. Braz J Periodontol. 2019; 29(3): 7-15.

37. SILVA CO, et al. Alongamento estético da coroa: resultados periodontais e centrados no paciente. Jornal de Periodontologia Clínica, 2015; 42 (12): 1126-1134.

38. SOUSA JNL, et al. Desenho digital do sorriso no planejamento interdisciplinar entre periodontia e prótese - relato de caso. Prosthes. Esthet. Sci. 2019; 8(30):55-67.

39. TRENTIN DS, et al. Os taninos que possuem efeito bacteriostático prejudicam a adesão de Pseudomonas aeruginosa e a formação de biofilme. PLoS One. 2013.

40. VARONI EM, et al. Plant polyphenols and oral health: old phytochemicals for new fields. Curr Med Chem, 19(11):1706-1720, 2012. 